\title{
Prevalence of orthorexia nervosa in university students and its relationship with psychopathological aspects of eating behaviour disorders
}

María-Laura Parra-Fernández', Teresa Rodríguez-Cano², María-Dolores Onieva-Zafra ${ }^{1 *}$ (D, María José Perez-Haro ${ }^{3}$, Víctor Casero-Alonso ${ }^{4}$, Elia Fernández-Martinez ${ }^{1}$ and Blanca Notario-Pacheco ${ }^{5}$

\begin{abstract}
Introduction: Orthorexia nervosa $(\mathrm{ON})$ is characterized by an obsession with healthy eating, which may lead to severe physical, psychological and social disorders. It is particularly important to research this problem in populations that do not receive clinical care in order to improve early detection and treatment.

Objective: The aim of this study was to research the prevalence of ON in a population of Spanish university students and to analyze the possible associations between $\mathrm{ON}$ and psychological traits and behaviors that are common to ED.

Method: A cross-sectional study with 454 students from the University of Castilla La Mancha, Spain. In total, 295 women and 159 men participated, aged between 18 and 41 years. The ORTO-11-ES questionnaire and the Eating Disorder Inventory (EDI-2) were used for this study. The chi squared test was used to compare the homogeneity among the different groups.

Results: The scores on the ORTO-11-ES suggested that 17\% of students were at risk of ON. The scores on the EDI-2 for the group at risk of ON were significant, compared to the remaining individuals, regarding their drive for thinness (17.1\% vs $2.1 \%$ ), bulimia (2.6\% vs $0 \%$ ), body dissatisfaction ( $26.3 \%$ vs. $12.4 \%)$, perfectionism (14.5\% vs $4.8 \%)$, interoceptive awareness (13.2\% vs 1.3\%), asceticism (15.8\% vs $3.7 \%$ ) and impulsiveness (9.2\% vs $1.9 \%)$.

Discussion and conclusion: These findings suggest that many of the psychological and behavioral aspects of ED are shared by people who are at risk of ON. Future research should use longitudinal data, examining the temporal relationship among these variables or other underlying variables that may contribute to the concurrence of $\mathrm{ED}$ and $\mathrm{ON}$.
\end{abstract}

Keywords: Orthorexia nervosa, Eating disorders, University students, Psychological traits, Behavioral traits

\section{Introduction}

The term 'eating disorders' (EDs) encompasses a variety of disorders characterized by abnormal eating behaviors associated with emotional difficulties. The EDs described in the fifth edition of the diagnostic and statistical manual of mental disorders (DSM-5) [1] may not be entirely applicable to specific populations due to the wide

\footnotetext{
* Correspondence: MariaDolores.Onieva@uclm.es

${ }^{1}$ Faculty of Nursing, University of Castilla-La-Mancha, Ciudad Real, Spain

Full list of author information is available at the end of the article
}

variability in the frequency, the time-period and the characteristics of each individual, limiting the application of available diagnostic criteria.

Orthorexia nervosa $(\mathrm{ON})$ is described as an obsession for healthy food. This term was used for the first time by Bratman in 1997 [2]. People who suffer from this eating fixation undergo a monomania for healthy food without artificial additives and are more concerned with the quality of food than the quantity [3]. This extreme concern for food can lead to a disorder with many different levels of severity. These patients 
have important dietary restrictions, which are related to medical disorders that are potentially mortal associated with malnutrition, affective instability and social isolation [3].

To date, neither the diagnostic criteria published for ON [4, 5], nor the different studies available have given enough clarity to include this disorder in the DSM-5 [1], nor in the tenth edition of the International Classification of Diseases (ICD-10) [6]. Furthermore, some studies have related $\mathrm{ON}$ with obsessive compulsive disorders (OCD) [7-10]. Donini et al. performed a study, in which they developed and validated a questionnaire to detect the risk of suffering ON: the ORTO-15 [11]. The same study reported an association between $\mathrm{ON}$ and OCD. In addition, most of the literature consulted by the authors of this study, reveals clinical characteristics of $\mathrm{ON}$ that are common in EDs, in particular in anorexia nervosa (AN) [12-15]. A study by Brytek-Matera found that the participants who displayed a great level of concern with healthy foods also showed a positive correlation with satisfaction and/or the appearance of their body, and therefore this is one of the characteristics that is also found in patients with AN [16]. A study developed by Vandereycken et al. showed that $\mathrm{ON}$ is a disorder that is often referred and acknowledged by patients with ED. According to this study, 67\% of professionals in charge of the treatment of these patients observed this phenomenon in their clinical practice, and $69 \%$ considered that the disorder warranted greater attention [17]. Both ED and ON are characterized by a lack of pleasure related with eating food and show a need for controlling the intake of food as a tool for improving their self-esteem and/or self-fulfillment, granting them a sense of control over their own life [18]. The difference between these two disorders is that, while people with orthorexia are focused on eating healthy and pure foods, preoccupied by quality, those who suffer from anorexia and/or bulimia are more concerned with the quantity of the foods they eat, rather than the quality of the same [19]. Vargas et al. point out that although the difference between both effectively resides in the final motivation, i.e. weight loss in AN or feeling healthy in the case of $\mathrm{ON}$, similar social and psychological consequences may exist in both disorders [20]. Furthermore, some authors attempt to identify or clarify the existing relationship between some EDs and mental disorders [21]. Dell'Osso et al. propose the hypothesis that people at risk of suffering $\mathrm{ON}$, besides sharing some traits with people who suffer autism spectrum disorders (ASDs) such as for example ritual-like behaviors when preparing food, may also share consequences such as the risk for social isolation [22].
Among the different studies available on the prevalence of $\mathrm{ON}$, several questionnaires [11, 23, 24] have been used to determine the presence of the disorder. Most of these are based on the proposal by Donini et al., i.e. the ORTO-15 [11]. Depending on the instrument used and the populations in which the study is performed, the results of the prevalence rates vary. One of the first studies performed in Italy by Donini et al. in 2004 using the ORTO-15 demonstrated a prevalence of $6.9 \%$ in a population of 404 students [25]. Kinzl et al. used the original test by Bratman in a sample of 283 dieticians, and found that $34.9 \%$ of the population had a high risk of ON [10]. In a study involving 446 German university students conducted by Depa et al. employing the Düsseldorfer Orthorexie Skala (DOS) [23], a 3.3\% estimated prevalence of $\mathrm{ON}$ was reported, together with a $9.0 \%$ prevalence for the risk of developing ON [26]. It is important to consider that most studies have been performed in non-clinical settings, and mainly on university students $[8,13,19,23,26,27]$.

Lifestyle habits and food consumption are developed since infancy and begin to establish themselves in adolescence and youth. The diet of youth, and especially that of university students is an important challenge, as it may involve important lifestyle changes [28]. The university population is an especially vulnerable group from the nutritional point of view, as they are beginning to take responsibility for their own dietary habits and they undergo a critical period in the consolidation of eating habits and behaviors [29]. Young adulthood (1924 years) is an important developmental period for exploring and establishing our relationship with health habits, beliefs and eating norms, as well as for body image development [30]. Considering that many of the conditions and behaviors established during teenage years persist throughout life, adolescence and adulthood, these periods represent powerful developmental opportunities for evaluating predictors and risk factors for ED. These behaviors should be addressed due to their adverse consequences such as metabolic risks later on in adulthood. Improving our understanding of populations who do not receive clinical care such as people with a risk of ED is particularly important for early detection and treatment of $\mathrm{ON}[31,32]$.

To date there is no data available on prevalence in the Spanish university population, or regarding the possible relations with characteristics that appear in other EDs.

Therefore, the aims of this study were to estimate the prevalence rate of $\mathrm{ON}$ in a Spanish university population with a tool that has been validated for this purpose and to determine the possible correlation of $\mathrm{ON}$ with psychological and behavioral aspects that appear in other EDs. The present study has considered indicators which are commonly associated with EDs: the body mass index 
(BMI) and sex, which will help us to clarify and further our understanding regarding this phenomenon.

\section{Method}

\section{Study design and subjects}

This cross-sectional study was planned and performed between January and May 2017, in Ciudad Real, Spain. We invited 800 university students from different faculties (Nursing, Law, Chemistry, Computer Science and Education), of which 454 university students participated (response rate: 56.75\%) including 295 women and 159 men, aged between 18 and 51 years (mean age, 21.74 \pm 4.73 years). The participants were recruited through informative talks delivered during university lectures in different faculties.

Data collection was performed via a questionnaire prepared by the researchers. The revised questionnaire was divided into three sections: (1) Sociodemographic characteristics; (2) the Eating Disorder Inventory-2 questionnaire (EDI-2) [33, 34]; and (3) the ORTO-11-ES [35, 36].

The University students voluntarily signed up to the study and they were asked to complete an online survey developed using the JotForm platform. It was assumed that the students who did not respond were within the same range of conditions as those who did. For ethical reasons, we were unable to research the causes which made these students decide not to participate.

\section{Ethical considerations}

The participants did not receive any financial incentive to take part in the study. Participants were informed that their information was to be kept confidential and would only be used for scientific purposes, obtaining the written informed consent of participants. The ethical committee of the Castilla-La Mancha University Hospital approved the study (Number C-45), according to the ethical principles for medical research gathered in the Declaration of Helsinki [37].

\section{Measurements}

\section{Demographic information}

The sociodemographic forms gathered information on the age, gender, height and weight of participants. The BMI of each participant was calculated based on the self-reported height and weight.

\section{Eating disorder inventory (EDI-2)}

This is a self-reported 91-item questionnaire, answered on a 6-point Likert-Type scale using a 3-point system where 'sometimes,' 'rarely', and 'never', are assigned zeros while 'often,' 'usually' and 'always' are assigned a score of 1,2 and 3, respectively. The questionnaire is used to assess eating-disorder symptoms, attitudes and behaviors. It contains 11 subscales: drive for thinness, body satisfaction, bulimia, effectiveness, perfectionism, interpersonal disruption, interoceptive awareness, maturity fears, asceticism, impulse regulation and social insecurity. The sub-scale scores can be calculated by simply adding the scores of all the items of each specific sub-scale. The EDI-2 total score ranges from 91 to 546 . We used a Spanish version of the scale validated by Corral, González, Pereña \& Seis dedos (1998), which showed an internal consistency of 0.83-0.92 [34].

The EDI-2 is widely used in Spain and it has been demonstrated to be a valid instrument for the accurate diagnosis and detection of the risk of ED [38-40] in the Spanish population. We chose to use the EDI-2 based on its good psychometric properties, in both clinical settings and non-clinical samples [33] as well as the possibility it offers for separately assessing different dimensions [41].

\section{ORTO-11- ES questionnaire}

The ORTO-15 questionnaire was originally developed in Italian [11]. This tool consists of 15 self-report multiplechoice items using a 4-point Likert-type scale (always, often, sometimes, never) to measure three underlying factors related to eating behavior: cognitive-rational (items 1 , 5, 6, 11, 12 and 14), clinical (items 3, 7, 8, 9 and 15) and emotional aspects (items 2, 4, 10 and 13). It is used to investigate obsessive behavior related to the selection, preparation, habits of food consumption and attitudes towards healthy food. The lower the score, the higher the indication of a behavior or attitude related to orthorexia. The Italian group [11] suggested a cut-off score of 40 points, whereby scores below this figure indicate $\mathrm{ON}$ related behavior.

For the present study, we have used the ORTO-11-ES [35] as a tool for assessing ON. This tool is based on a structure of three factors for the abbreviated 11-item version, and has demonstrated an appropriate internal consistency (Cronbach's alpha $=0.80$ ). Furthermore, the test has demonstrated a good predictive capacity for a threshold value of $<25$ (79.5\% effectiveness, $75 \%$ sensitivity and specificity $79.6 \%$ ).

\section{Statistical analyses}

An exploratory statistical analysis of all the demographic variables and the ON-tendencies was carried out. Quantitative features were described by the median and the inter-quartile range (IQR) and qualitative variables were described using frequencies and percentages.

To identify the score differences among the different groups (individuals with $\mathrm{ON}$ tendencies and individuals without $\mathrm{ON}$ tendencies) and without an assumption of normality for scores and small sample sizes $(N<30)$ for some of the subgroups, the Wilcoxon-Mann-Whitney 
(W-M-N) and Kruskal-Wallis (K-W) tests for independent samples were performed.

For each feature (gender, smoker and BMI), the prevalence of $\mathrm{ON}$ was calculated as the proportion of individuals of a certain population that are under risk of suffering $\mathrm{ON}$ in this period.

This analysis has also been performed for each sub-scale of the Eating Disorder Inventory-2, i.e. for Drive for Thinness, Bulimia, Body Dissatisfaction, Ineffectiveness, Perfectionism, Interpersonal Distrust, Interoceptive Awareness, Maturity Fears, Asceticism, Impulse Regulation and Social Insecurity. Moreover, a correlation analysis was performed between the scores of the sub-scales of the EDI-2 and the scores of the ORTO-11-ES, using the Spearman coefficient.

The significance level was established at $p<.05$ for all cases. The $\mathrm{R}$ statistical software was used to perform all the statistical analyses [42].

\section{Results}

The sample included 454 students recruited from the Castilla-La Mancha University, and who voluntarily answered the questionnaire. A summary of the demographic variables is shown in Table 1.

The mean score obtained by the total participants regarding the ORTO-11-ES questionnaire was 27.78 and the standard deviation was \pm 3.34 . The cut-off score was established at $<25$ [35] ranging from 16 to 36 points, with $76(17 \%)$ participants under risk of suffering ON.

The location parameter for the age, in those who were under a true risk of suffering $\mathrm{ON}$, was not significantly different from those who were not under a real risk (W-M-N $=12,917, p=.16$ ), neither was it significant for gender (W-M-N=22,916, $p=.69)$. The BMI variable was categorized into three groups, 1) below 18.5 (thinness); 2 ) 18.5, 24.9 (normal weight); 3) 25-41 (obesity). The differences of the ORTO-11-ES scores among the three groups were also non-significant (K-W $\left.\mathrm{X}^{2}(2)=1.9466 p=.38\right)$. On the other hand, statistical differences were found for smokers (W $=13,462, p=.00)$.

Table 1 Descriptive analysis of the sample

\begin{tabular}{lll}
\hline Qualitative variable & & Frequency \\
Smoker & Yes & $92(20.30 \%)$ \\
& No & $362(79.70 \%)$ \\
Sex & Female & $295(65.00 \%)$ \\
& Male & $159(35.00 \%)$ \\
Marital Status & Single & $444(97.8 \%)$ \\
& Married & $10(2.20 \%)$ \\
Quantitative variable & & Median (IQR) \\
Age & & $20.00(19.00-22.00)$ \\
Body Mass Index & & $22.21(20.31-24.50)$ \\
\hline
\end{tabular}

\section{Prevalence and features of orthorexia nervosa}

The prevalence of $\mathrm{ON}$ is significantly higher in women, as reported in the Italian population. [43]. There are no significant differences among the other groups. (See Table 2).

Concerning the ED, the analysis suggests that the individuals at risk of suffering $\mathrm{ON}$ have a higher prevalence rate of drive for thinness $(17.1 \%$ vs $2.1 \%, \chi 2(1)=32.22, p$ $=.00)$, bulimia $(2.6 \%$ vs $0 \%, \mathrm{x} 2(1)=9.99, \mathrm{p}=.00)$, body dissatisfaction $(26.3 \%$ vs. $12.4 \%, \mathrm{X} 2(1)=9.6, \mathrm{p}=.00)$, perfectionism $(14.5 \%$ vs $4.8 \%, \mathrm{x} 2(1)=9.98, \mathrm{p}=.00)$, interoceptive awareness $(13.2 \%$ vs $1.3 \%, \mathrm{X} 2(1)=27.74, \mathrm{p}=.00)$, asceticism $(15.8 \%$ vs $3.7 \%, \mathrm{x} 2(1)=17.12, \mathrm{p}=.00)$ and impulse regulation $\left(9.2 \%\right.$ vs $\left.1.9 \%, \chi^{2}(1)=11.46, \mathrm{p}=.00\right)$ than people who are not at a risk of suffering this disorder (see Table 3).

In addition, a correlation analysis of the ED sub-scale scores and the ON scores has been carried out (see Table 4). Due to the lack of normality in all the scores, the Spearman correlation coefficient was calculated. All of these tests were negative and statistically significant $(p<0.05)$. The negative sign indicates that, in general, high values of the ED subscales correspond to low values for the ON scores. The highest (negative) correlation coefficient $(-0.564, p=0.00)$ was found between drive for thinness and the ON score.

\section{Discussion and conclusion}

The aim of the present study was to determine the prevalence of suffering $\mathrm{ON}$ and its possible relation with psychological and behavioral aspects of ED in a population of Spanish university students. We used the ORTO-11-ES [35], our findings reveal that 17\% (76 students) of the sample presented a high risk of suffering from ON. This percentage is far from that obtained in the unique study on ON conducted on a sample of the Spanish population, where the results showed a prevalence of $86 \%$ [44]. However, this pilot study did not use a validated translation of the original ORTO-15 [11], rather it used the English version on a sample of 136 ex-students of Ashtanga yoga. Moreover, the age range of participants in the aforementioned study was higher than the age of university students [44]. Dunn et al. [45] found that $1.0 \%$ of students in

Table 2 Prevalence of Orthorexia for each feature

\begin{tabular}{llllc}
\hline Feature & Prevalence of ON (\%) & $x^{2}$ & DF & $p$-value \\
\hline Male & 11.9 & 4.03 & 1 & $\mathbf{. 0 4}$ \\
Female & 19.3 & & & \\
Smoker & 18.0 & 1.89 & 1 & .17 \\
Non-smoker & 12.0 & & & \\
BMl: Thinness & 25.0 & 1.95 & 2 & .38 \\
BMl: Normal weight & 16.2 & & & \\
BMl: Obesity & 15.4 & & & \\
\hline
\end{tabular}

Bold data indicates statistically significance $(p<.05)$ indicated bold data 
Table 3 Prevalence of eating disorders in a population at risk of $\mathrm{ON}$ and in a healthy population

\begin{tabular}{lllllll}
\hline Dimension EDI-2 & \multicolumn{2}{l}{ Orthorexia Nervosa } & \multirow{2}{l}{$x^{2}$} & df & $p$-value \\
\cline { 2 - 4 } & Yes (\%) & No (\%) & & & \\
\hline Drive for thinness & 17.1 & 2.1 & 32.22 & 1 & $\mathbf{. 0 0}$ \\
Bulimia & 2.6 & 0.0 & 9.99 & 1 & $\mathbf{. 0 0}$ \\
Body Dissatisfaction & 26.3 & 12.4 & 9.69 & 1 & $\mathbf{. 0 0}$ \\
Ineffectiveness & 9.2 & 4.0 & 3.77 & 1 & .05 \\
Perfectionism & 14.5 & 4.8 & 9.98 & 1 & $\mathbf{. 0 0}$ \\
Interpersonal Distrust & 6.6 & 8.7 & 0.38 & 1 & .54 \\
Interoceptive Awareness & 13.2 & 1.3 & 27.74 & 1 & $\mathbf{. 0 0}$ \\
Maturity Fears & 22.4 & 14.3 & 3.13 & 1 & .08 \\
Asceticism & 15.8 & 3.7 & 17.12 & 1 & $\mathbf{. 0 0}$ \\
Impulse regulation & 9.2 & 1.9 & 11.46 & 1 & $\mathbf{. 0 0}$ \\
Social Insecurity & 11.8 & 8.5 & 0.88 & 1 & .35 \\
\hline
\end{tabular}

Bold data indicates statistically significance $(p<.05)$ indicated bold data

the United States suffered from $\mathrm{ON}$ and suggested that $10.0 \%$ of the population was at risk of developing this disorder. In Italian populations, different studies place the prevalence of $\mathrm{ON}$ in a range of between 6.9 to $57.6 \%$ [25, 46]. In Turkey, a validated adaptation of this tool, the ORTO-11, showed a prevalence of approximately $45 \%$ in different studies with samples of university healthcare students $[8,13]$. The greatest prevalence, $74.2 \%$, was reported in a study conducted in Hungary, also using a translated and validated version of ORTO-11-Hu in a sample of university students [19]. Considering the varying results obtained across different countries, in part, some of these differences may be explained by socio-cultural factors, being closely related with the eating habits linked to the culture of each country [7, 47]. However, other authors attribute these differences to the structure of the questionnaire itself rather than cultural problems [48]. Furthermore, when interpreting these results, it is important to

Table 4 Correlation analysis of the EDI-2 sub-scales scores and the ON scores

\begin{tabular}{lll}
\hline Dimension EDI-2 & Spearman coefficient & $p$-value \\
\hline Drive for thinness & -0.564 & 0.00 \\
Bulimia & -0.260 & 0.00 \\
Body Dissatisfaction & -0.347 & 0.00 \\
Ineffectiveness & -0.228 & 0.00 \\
Perfectionism & -0.248 & 0.00 \\
Interpersonal Distrust & -0.147 & 0.00 \\
Interoceptive Awareness & -0.344 & 0.00 \\
Maturity Fears & -0.113 & 0.02 \\
Asceticism & -0.168 & 0.00 \\
Impulse regulation & -0.210 & 0.00 \\
Social Insecurity & -0.148 & 0.00 \\
\hline
\end{tabular}

consider that the prevalence is linked to the interpretation of different versions of a self-reported questionnaire, which have used different cut-off points [11, 36, 49, 50] .

A significant correlation between $\mathrm{ON}$ and the psychopathological characteristics of other EDs, was observed based on the variables included in the EDI-2 subscales: drive for thinness, bulimia symptoms, body dissatisfaction, perfectionism, interoceptive awareness, asceticism and impulsiveness. These findings highlight the possible relation between the risk of suffering $\mathrm{ON}$ and the diagnosis of ED. Some of our results reinforce findings from previous studies [51, 52]. In a sample of 220 university students, Barnes et al. [51] concluded that there was a positive relation between $\mathrm{ON}$ and other $\mathrm{ED}$, regarding the body image attitude and the perfectionist personality of these individuals. Also, having a personal history of having suffered an ED was found to be a strong predictor for ON. Another study, also along these lines, performed with 459 university students in the United States, showed a positive correlation between ON and perfectionism [52]. Two further clinical studies also highlighted the close relation between ED and ON [23, 53]. One of these, conducted in Germany with a sample of 1122 hospitalized patients with psychiatric diagnoses found positive correlations between $\mathrm{ON}$ and the dimensions drive for thinness, interoceptive awareness and asceticism in patients diagnosed with ED [53]. The second study was performed with another tool for the detection of ON: the Dußßdorfer Orthorexie "DOS" scale [23]. This study included a sample of 1340 participants and found positive correlations with the EDI-2 subscales of thinness, bulimia and body dissatisfaction, suggesting proximity between ON and ED [23]. Currently, there is much debate surrounding the relationship between AN and $\mathrm{ON}$, ranging from how to classify and differentiate these disorders, in some cases considering $\mathrm{ON}$ as a new disorder, or a subset of AN [53]. It is well known that undertaking weight-loss diets can lead certain individuals towards adopting extreme eating habits. There is a large coincidence between supposedly 'healthy' foods and generally 'slimming' foods which can lead individuals towards a confusion that is difficult to manage [23]. At times, this may lead to an obsession with healthy eating, until individuals adopt a more severe pathology, such as AN [17]. On the other hand, the opposite hypothesis can lead us to affirm that an orthorexic behavior can be interpreted as a phase or a tendency in patients who have been previously diagnosed with ED and are in a recovery phase, and who, displaying an improvement of symptoms, can end up developing orthorexic behaviors $[18,41]$. These findings emphasize how concerns regarding healthy eating can act as a predisposing factor for developing AN or Bulimia nervosa (BN), and as a key residual symptom which may potentially 
favor relapses of the illness $[54,55]$. Only with further research studies on clinical samples can we reveal the relationship between these two pathologies, and determine whether ON may be a factor that predicts the development of AN or viceversa.

Another aim of our study was to explore the relationship of ON with variables such as gender, age, weight, and body mass index. We found significant differences for the mean score on the ORTO-11-ES [35] scale in the female population. If we compare this with other studies, this result is striking as in most studies no differences were found regarding gender $[8,44,52,56]$. In the study by Donini et al., they concluded that men are more sensitive to suffering from this problem [11]. This result has been repeated in one other study performed on a sample of Turkish students $[13,25]$. However, there are other studies, which, like ours, report a greater proportion of women at risk of developing $\mathrm{ON}[7,13,57]$. Although the gender difference of $\mathrm{ON}$ is harder to detect, in part, due to the lack of research in clinically diagnosed individuals [58], undoubtedly, gender is a critical factor in many aspects of life, including the attitudes and perceptions of one's body image [59]. Indeed, there are a series of characteristics related to the internalization and externalization of emotions which may explain the different prevalence rates by gender in many mental illnesses [60].

Regarding the BMI, our results failed to find a significant correlation of the same with $\mathrm{ON}$, a finding that supports most previous studies performed in different populations $[56,61]$. In a study conducted by Aksoydan et al. in a population of 94 . Turkish artists, no differences were found between the mean ORTO-15 score and the BMI [56]. Also, another study performed in Poland with 400 participants aged between 18 and 35 years failed to find a significant correlation with the BMI [61]. Varga et al. found that the association between the ON scores and the BMI was statistically significant, albeit insignificant [19]. Some authors suggest that the BMI can predict orthorexic behaviors in combination with other variables such as medical reasons, diet and healthy nutrition [7]. In contrast, another study also performed in Turkey on 878 medical students with a mean age of $21.3 \pm 2.1$ years found that, as the BMI increased, the ON score decreased, and, therefore, the risk of orthorexia nervosa increased [27]. Some authors justify this on the basis that overweight and obesity can expose the individual to humiliation and force the person to diet and consume healthy foods [13] .

Although this study is one of the first to examine the prevalence of $\mathrm{ON}$ in Spain, there are several limitations worth considering. First, the results do not provide information on the mechanisms that underlie the relationship between $\mathrm{ON}$ and EBD; for example, by considering other underlying factors such as biological factors, and personality, which could contribute to the high concurrence of these behaviors. Due to the cross-sectional design of this study, we cannot determine the time course of the development of EDs and $\mathrm{ON}$. Therefore, by considering $\mathrm{ON}$ as a potential risk factor for developing an ED, a more complete longitudinal study is necessary in the future. Despite these limitations, the current study focuses on a gap in the literature regarding $\mathrm{ON}$ and $\mathrm{EBD}$, broadly demonstrating the relationship between these.

Our results highlight the long path ahead for the scientific community, in order to recognize that $\mathrm{ON}$ can be included as another diagnosis within eating disorders. Additional studies are needed to describe the behavior of people with orthorexia (i.e. their etiology, diagnosis, treatment and the prevention of the same). On the other hand, studies on these subjects provide the health professional with the information necessary to be able to identify individuals with orthorexic behavior and thus provide appropriate treatment to derive the patient towards the most appropriate resource.

\section{Abbreviations \\ AN: Anorexia nervosa; BMl: Body mass index; BN: Bulimia nervosa; \\ DOS: Düsseldorf Orthorexie Skala; DSM-5: Diagnostic and statistical manual of mental disorders; ED: Eating disorder; EDI-2: Eating Disorder Inventory; ICD- \\ 10: International Classification of Diseases; IQR: Inter-quartile range; \\ OCD: Obsessive compulsive disorders; ON: Orthorexia nervosa; ORTO-11- \\ ES: Spanish version Test for the diagnosis of Orthorexia nervosa; ORTO- \\ 15: Test for the diagnosis of orthorexia}

\section{Acknowledgements}

The authors thank the students who took part in this study and generously granted us their time and provided us details about their experiences in clinical practice.

\section{Funding}

The authors did not receive any funding for this paper.

\section{Availability of data and materials}

The datasets used and analyzed during the current study are available from the corresponding author on reasonable request.

\section{Authors' contributions}

Study conception and design: P-F ML, R-C T, O-Z MD, F- M E, N-P B. Data collection, statistical expertise, analysis and interpretation of data: P-H MJ, C-A V, P-F ML, O-Z MD. Manuscript preparation, supervision, administrative support and critical revision of the paper. P-F ML, R-C T, O-Z MD, F- M E, N-P B. All authors read and approved the final manuscript.

\section{Ethics approval and consent to participate}

Ethical approval for the study was obtained from the Research Ethics Committee - number C - 45. All procedures were followed in accordance with the Helsinki Declaration. Before data were collected, all students were informed of the purpose of the study and informed written consent was obtained. In addition, all participants were assured that their anonymity and confidentiality would be maintained and that they were entitled to drop out of the study at any time.

Consent for publication

"Not applicable"

Competing interests

The authors declare that they have no competing interests. 


\section{Publisher's Note}

Springer Nature remains neutral with regard to jurisdictional claims in published maps and institutional affiliations.

\begin{abstract}
Author details
'Faculty of Nursing, University of Castilla-La-Mancha, Ciudad Real, Spain. ${ }^{2}$ Head of Mental Health, Castilla la Mancha Health Services, Ciudad Real, Spain. ${ }^{3}$ Biostatech Advice, Training and Innovation in Biostatistics, S.L Santiago de Compostela, A Coruña, Spain. ${ }^{4}$ School of Industrial Engineers, University of Castilla-La Mancha, Ciudad Real, Spain. ${ }^{5}$ Faculty of Nursing, University of Castilla-La-Mancha, Cuenca, Spain.
\end{abstract}

Received: 2 July 2018 Accepted: 25 October 2018 Published online: 13 November 2018

\section{References}

1. American Psychiatric Association. Guía de consulta de los criterios diagnósticos del DSM-5 ${ }^{\oplus}$ [Internet]. American Psychiatric Publishing; 2013.

2. Bratman S. Health food junkie. Bratman S Heal Food Junkie Yoga J. 1997: 42-50 Available: https://www.google.es/?gws_rd=ssl.

3. Brytek-Matera A. Orthorexia nervosa-an eating disorder, obsessivecompulsive disorder or disturbed eating habit? Arch Psychiatry Psychother 2012;1:55-60.

4. Moroze RM, Dunn TM, Craig Holland J, Yager J, Weintraub P. Microthinking about micronutrients: a case of transition from obsessions about healthy eating to near-fatal "orthorexia nervosa" and proposed diagnostic criteria. Psychosomatics. 2015. https://doi.org/10.1016/j.psym.2014.03.003.

5. Dunn TM, Bratman S. On orthorexia nervosa: a review of the literature and proposed diagnostic criteria. Eat Behav. 2016;21:11-7. https://doi.org/10. 1016/j.eatbeh.2015.12.006.

6. World Health Organization. The ICD-10 classification of mental and behavioural disorders : clinical descriptions and diagnostic guidelines. [Internet]. World Health. Organization; 1992. Available: www.who.int/ classifications/icd/en/.

7. Arusoğlu G, Kabakçi E, Köksal G, Merdol TK. Orthorexia nervosa and adaptation of ORTO-11 into Turkish. Turk Psikiyatri Derg. 2008;19: 283-91. Available. http://www.ncbi.nlm.nih.gov/pubmed/18791881.

8. Tuïay Bag Cı Bosi A, Derya C-A, Atay Guïer C-A. Prevalence of orthorexia nervosa in resident medical doctors in the faculty of medicine (Ankara, Turkey). Appetite. 2007;49: 661-666. doi:https://doi.org/10.1016/j.appet.2007.04.007

9. Kinzl JF, Hauer K, Traweger C, Kiefer I. Orthorexia nervosa in dieticians. Psychother Psychosom Karger Publishers. 2006;75:395-6. https://doi.org/10.1159/000095447.

10. Mathieu J. What is orthorexia? J am diet Assoc. Elsevier. 2005;105:1510-2. https://doi.org/10.1016/J.JADA.2005.08.021.

11. Donini LM, Marsili D, Graziani MP, Imbriale M, Cannella C. Orthorexia nervosa: validation of a diagnosis questionnaire. Eat Weight Disord. 2005;10. https://doi.org/10.1007/BF03327537.

12. Bartrina AJ. Ortorexia o la obsesion por la dieta saludable. Arch Latinoam Nutr. 2007;57:313-5 Available: https://www.alanrevista.org/ediciones/2007/4/ art-2/.

13. Fidan T, Ertekin V, Işikay S, Kirpinar I. Prevalence of orthorexia among medical students in Erzurum. Turkey Compr Psychiatry. 2010;51:49-54. https://doi.org/10.1016/j.comppsych.2009.03.001.

14. Kummer A, Dias FMV, Teixeira AL. On the concept of orthorexia nervosa: letter to the editor. Scand J Med Sci Sport. 2008;18:395-6. https://doi.org/10. 1111/j.1600-0838.2008.00809.x.

15. Gramaglia C, Brytek-Matera A, Rogoza R, Zeppegno P. Orthorexia and anorexia nervosa: two distinct phenomena? A cross-cultural comparison of orthorexic behaviours in clinical and non-clinical samples. BMC Psychiatry. BioMed Central. 2017;17:75. https://doi.org/10.1186/s12888-017-1241-2.

16. Brytek-Matera A, Donini LM, Krupa M, Poggiogalle E, Hay P. Orthorexia nervosa and self-attitudinal aspects of body image in female and male university students. J Eat Disord. 2015;3:2. https://doi.org/10.1186/ s40337-015-0038-2.

17. Vandereycken W. Media hype, diagnostic fad or genuine disorder? Professionals' opinions about night eating syndrome, orthorexia, muscle dysmorphia, and emetophobia. Eat Disord. 2011;19:145-55. https://doi.org/ 10.1080/10640266.2011.551634.
18. Segura-Garcia C, Ramacciotti C, Rania M, Aloi M, Caroleo M, Bruni A, et al. The prevalence of orthorexia nervosa among eating disorder patients after treatment. Eat Weight Disord. 2015. https://doi.org/10.1007/s40519-014-0171-y.

19. Varga M, Thege BK, Dukay-Szabó S, Túry F, van Furth EF, Bratman S, et al. When eating healthy is not healthy: orthorexia nervosa and its measurement with the ORTO-15 in Hungary. BMC Psychiatry. BioMed Central. 2014;14:59. https://doi.org/10.1186/1471-244X-14-59.

20. Varga M, Dukay-Szabó S, Túry F, van Furth EF, van Furth Eric F. Evidence and gaps in the literature on orthorexia nervosa. Eat Weight Disord. 2013;18 103-11. https://doi.org/10.1007/s40519-013-0026-y.

21. Dell'Osso L, Carpita B, Gesi C, Cremone IM, Corsi M, Massimetti E, et al. Subthreshold autism spectrum disorder in patients with eating disorders. Compr Psychiatry WB Saunders. 2018;81:66-72. https://doi.org/10.1016/J. COMPPSYCH.2017.11.007.

22. Pini S, Abelli M, Carpita B, Dell'Osso L, Castellini G, Carmassi C, et al. Historical evolution of the concept of anorexia nervosa and relationships with orthorexia nervosa, autism, and obsessive-compulsive spectrum. Neuropsychiatr Dis Treat. 2016;12:1651-60. https://doi.org/10.2147/NDT.S108912.

23. Barthels F, Meyer F, Pietrowsky R. Die Düsseldorfer Orthorexie SkalaKonstruktion und Evaluation eines Fragebogens zur Erfassung orthorektischen Ernährungsverhaltens. Z Klin Psychol Psychother. 2015;44:97-105. https://doi.org/10.1026/1616-3443/a000310.

24. Bauer SM, Fusté A, Andrés A, Saldaña C. The Barcelona Orthorexia Scale (BOS): development process using the Delphi method. Eating and Weight Disorders. 3 Aug 2018. https://doi.org/10.1007/s40519-018-0556-4

25. Donini LM, Marsili D, Graziani MP, Imbriale M, Cannella C. Orthorexia nervosa: a preliminary study with a proposal for diagnosis and an attempt to measure the dimension of the phenomenon. Eat Weight Disord. 2004;9: 151-7. https://doi.org/10.1007/BF03325060.

26. Depa J, Schweizer J, Bekers S-K, Hilzendegen C, Stroebele-Benschop N. Prevalence and predictors of orthorexia nervosa among German students using the 21-item-DOS. Bulim Obes: Eat Weight Disord - Stud Anorexia; 2016. https://doi.org/10.1007/s40519-016-0334-0.

27. Asil E, Sürücüoğlu MS. Orthorexia nervosa in Turkish dietitians. Ecol Food Nutr. 2015;54:303-13. https://doi.org/10.1080/03670244.2014.987920.

28. Cervera Burriel F, Serrano Urrea R, Vico García C, Milla Tobarra M, García Meseguer MJ. Hábitos alimentarios y evaluación nutricional en una población universitaria. Nutr Hosp. Grupo Arán S.L. 2013;28:438-46. https:// doi.org/10.3305/NH.2013.28.2.6303.

29. Sánchez Socarrás $V$, Aguilar Martínez A. Food habits and health-related behaviors in a university population. Nutr Hosp. 2014;31:449-57. https://doi. org/10.3305/nh.2015.31.1.7412.

30. Nelson MC, Story M, Larson NI, Neumark-Sztainer D, Lytle LA. Emerging adulthood and college-aged youth: an overlooked age for weight-related behavior change. Obesity. 2008;16:2205-11. https://doi.org/10.1038/oby. 2008.365.

31. Becker AE, Franko DL, Nussbaum K, Herzog DB. Secondary prevention for eating disorders: the impact of education, screening, and referral in a college-based screening program. Int J Eat Disord. 2004;36:157-62. https:// doi.org/10.1002/eat.20023.

32. Tavolacci MP, Grigioni S, Richard L, Meyrignac G, Déchelotte P, Ladner J. Eating Disorders and Associated Health Risks Among University Students. J Nutr Educ Behav. Elsevier. 2015;47:412-420.e1. https://doi.org/10.1016/J. JNEB.2015.06.009.

33. Garner D. Eating Disorder Inventory -2,EDI-2.Proffesional Manual. odessa: Psychological Assessment. Resources. 1991.

34. Corral S, González M, Pereña J SN. Adaptación española del Inventario de trastornos de la conducta alimentaria. EDI-2: Inventario de Trastornos de la Conducta Alimentaria. [Internet]. Madrid:TEA; 1998.

35. Parra-Fernandez ML, Rodríguez-Cano T, Onieva-Zafra MD, Perez-Haro MJ, Casero-Alonso V, Muñoz Camargo JC, et al. Adaptation and validation of the Spanish version of the ORTO-15 questionnaire for the diagnosis of orthorexia nervosa. Manalo E, editor. PLoS One. 2018;13: e0190722. https:// doi.org/10.1371/journal.pone.0190722

36. Parra-Fernandez ML, Rodríguez-Cano T, Perez-Haro MJ, Onieva-Zafra MD, Fernandez-Martinez E, Notario-Pacheco B. Structural validation of ORTO-11-ES for the diagnosis of orthorexia nervosa. Bulim Obes: Spanish version. Eat Weight Disord - Stud Anorexia; 2018. https:/doi.org/10.1007/s40519-018-0573-3.

37. Declaración de Helsinki - WMA - The World Medical Association [Internet]. [cited 26 Feb 2018]. Available: https://www.wma.net/what-we-do/medicalethics/declaration-of-helsinki/ 
38. Castro-Zamudio S, Castro-Barea J. Impulsividad y búsqueda de sensaciones: factores asociados a síntomas de anorexia y bulimia nerviosas en estudiantes de secundaria. Escritos Psicol / Psychol Writings Escritos de Psicologia. 2016;9:22-30. https://doi.org/10.5231/psy.writ.2016.2706.

39. Rojo-Moreno L, Iranzo-Tatay C, Gimeno-Clemente N, Barber-Fons MA, Rojo-Bofill LM, Livianos-Aldana L. Genetic and environmental influences on psychological traits and eating attitudes in a sample of Spanish schoolchildren. Rev Psiquiatr y Salud Ment (English Ed. Elsevier). 2017. https://doi.org/10.1016/j.rpsmen.2017.05.006.

40. Fernández-Delgado A, Jáuregui-Lobera I. Variables Psicológicas Y psicopatológicas Asociadas a los trastornos de la conducta alimentaria (TCA) Variables psicológicas y psicopatológicas asociadas con trastornos de la alimentación (ED). J Negat No Posit Results. 2016;1:71-80 Available: http://revistas.proeditio.com/jonnpr/article/view/1011/pdf1011.

41. Barthels F, Meyer F, Huber T, Pietrowsky R. Orthorexic eating behaviour as a coping strategy in patients with anorexia nervosa, Eat Weight Disord - Stud Anorexia, Bulim Obes. Springer International Publishing. 2016:1-8. https://doi.org/10.1007/s40519-016-0329-X.

42. Rosseel Y. lavaan: An R Package for Structural Equation Modeling. J Stat Softw. 2012:48:1-36. https://doi.org/10.18637/jss.v048.i02.

43. Dell'Osso L, Abelli M, Carpita B, Massimetti G, Pini S, Rivetti L, et al. Orthorexia nervosa in a sample of Italian university population. Riv Psichiatr. 51:190-6. https://doi.org/10.1708/2476.25888.

44. Herranz Valera J, Acuña Ruiz P, Romero Valdespino B, Visioli F. Prevalence of orthorexia nervosa among ashtanga yoga practitioners: a pilot study. Eat Weight Disord - Stud Anorexia, Bulim Obes. 2014;19:469-72. https://doi.org/ 10.1007/s40519-014-0131-6.

45. Dunn TM, Gibbs J, Whitney N, Starosta A. Prevalence of orthorexia nervosa is less than 1\%: data from a US sample. Eat Weight Disord. 2016;22:185-92. https://doi.org/10.1007/s40519-016-0258-8

46. Bo S, Zoccali R, Ponzo V, Soldati L, De Carli L, Benso A, et al. University courses, eating problems and muscle dysmorphia: are there any associations? J Transl Med. 2014;12:221. https://doi.org/10.1186/s12967-0140221-2.

47. Varga M, Dukay-Szabo S, Túry F. orthorexia nervosa and it's background factors. Ideggyogy Sz, Available. 2013;66:220-7 http://www.ncbi.nlm.nih.gov/ pubmed/23971352.

48. Missbach B, Hinterbuchinger B, Dreiseitl V, Zellhofer S, Kurz C, König J. When Eating Right, Is Measured Wrong! A Validation and Critical Examination of the ORTO-15 Questionnaire in German. Manalo E, editor. PLoS One. 2015;10: e0135772. https://doi.org/10.1371/journal.pone.0135772

49. Hyrnik J, Janas-Kozik M, Stochel M, Jelonek I, Siwiec A, Rybakowski JK. The assessment of orthorexia nervosa among 1899 polish adolescents using the ORTO-15 questionnaire. Int J Psychiatry Clin Pract. 2016;20:199-203. https://doi.org/10.1080/13651501.2016.1197271.

50. Ramacciotti CE, Perrone P, Coli E, Burgalassi A, Conversano C, Massimetti G, et al. Orthorexia nervosa in the general population: a preliminary screening using a self-administered questionnaire (ORTO-15). Eat weight Disord, Available. 2011;16:e127-30 http://www.ncbi.nlm.nih.gov/pubmed/21989097.

51. Barnes MA, Caltabiano ML. The interrelationship between orthorexia nervosa, perfectionism, body image and attachment style. Eat weight Disord - stud anorexia, Bulim Obes. Springer International Publishing. 2017; 22:177-84. https://doi.org/10.1007/s40519-016-0280-x.

52. Oberle CD, Samaghabadi RO, Hughes EM. Orthorexia nervosa: assessment and correlates with gender, BMI, and personality. Appetite Academic Press. 2017;108:303-10. https://doi.org/10.1016/J.APPET.2016.10.021.

53. Andreas S, Schedler K, Schulz H, Nutzinger DO. Evaluation of a German version of a brief diagnosis questionnaire of symptoms of orthorexia nervosa in patients with mental disorders (Ortho-10). Eat weight Disord stud anorexia, Bulim Obes. Springer International Publishing. 2018;23:75-85. https://doi.org/10.1007/s40519-017-0473-y.

54. Koven NS, Abry AW. The clinical basis of orthorexia nervosa: emerging perspectives. Neuropsychiatr Dis Treat Dove Press. 2015;11:385-94. https://doi.org/10.2147/NDT.S61665.

55. Dell'Osso L, Carpita B, Muti D, Cremone IM, Massimetti G, Diadema E, et al. Prevalence and characteristics of orthorexia nervosa in a sample of university students in Italy. Eat Weight Disord - Stud Anorexia, Bulim Obes. Springer International Publishing. 2017:1-11. https://doi.org/10.1007/s40519017-0460-3

56. Aksoydan E, Camci N. Prevalence of orthorexia nervosa among Turkish performance artists. Eat Weight Disord. 2009;14:33-7 doi:6158 [pii].
57. Koven NS, Senbonmatsu R. A neuropsychological evaluation of orthorexia nervosa. Open J Psychiatry Scientific Research Publishing. 2013;03:214-22. https://doi.org/10.4236/ojpsych.2013.32019.

58. Brytek-Matera A, Rogoza R, Gramaglia C, Zeppegno P. Predictors of orthorexic behaviours in patients with eating disorders: a preliminary study. BMC Psychiatry. BioMed Central. 2015;15:252. https://doi.org/10.1186/ s12888-015-0628-1.

59. Blashill AJ. Gender roles, eating pathology, and body dissatisfaction in men: a meta-analysis. Body Image. 2011;8:1-11. https://doi.org/10.1016/j.bodyim. 2010.09.002.

60. Wills TA, Simons JS, Sussman S, Knight R. Emotional self-control and dysregulation: a dual-process analysis of pathways to externalizing/ internalizing symptomatology and positive well-being in younger adolescents. Drug Alcohol Depend Elsevier. 2016;163:S37-45. https://doi. org/10.1016/J.DRUGALCDEP.2015.08.039.

61. Brytek-Matera A, Krupa M, Poggiogalle E, Donini LM. Adaptation of the ORTHO-15 test to polish women and men. Eat Weight Disord. 2014;19:69_ 76. https://doi.org/10.1007/s40519-014-0100-0.

\section{Ready to submit your research? Choose BMC and benefit from:}

- fast, convenient online submission

- thorough peer review by experienced researchers in your field

- rapid publication on acceptance

- support for research data, including large and complex data types

- gold Open Access which fosters wider collaboration and increased citations

- maximum visibility for your research: over 100M website views per year

At BMC, research is always in progress.

Learn more biomedcentral.com/submissions 